\title{
Students' trajectories through higher education: a review of quantitative research
}

\section{Christina Haas $^{1} \cdot$ Andreas Hadjar $^{1}$}

Published online: 31 October 2019

(C) The Author(s) 2019

\begin{abstract}
With the increasing availability of high-quality longitudinal data on students in higher education, scholars' interest in how students proceed through higher education has risen. So far, the research field is diverse in theoretical perspectives and methodological approaches. Thus, based on 27 studies published in (higher) education research journals during the past two decades, this literature review provides an overview of the theoretical concepts, methodologies and main empirical findings in the study of students' trajectories in higher education. The results depict a US dominated research field. Most theoretical frameworks are based on student's decision-making. Across different country contexts and research designs - ranging from descriptions of student trajectories to studies predicting who engages in which types of trajectories to sequential trajectory reconstruction - we found that historically disadvantaged groups in higher education such as students from low social origin follow less linear and less smooth higher education trajectories. However, while the field of comparative education is growing steadily and may significantly contribute to explaining the link between the realization of students' opportunities and the way how higher education is designed and implemented both on the national and local level, there were no cross-country comparison studies on higher education trajectories.
\end{abstract}

Keywords Literature review · Trajectories $\cdot$ Higher education pathways $\cdot$ Longitudinal designs · Study patterns $\cdot$ Study progress $\cdot$ Panel data

\section{Introduction}

While researchers, higher-education (HE) counsellors and policymakers rely on indicators such as access, enrolment and graduation rates, students' HE trajectories-and thus

Christina Haas

Christina.haas@uni.lu

1 Institute of Education and Society, University of Luxembourg, Avenue de l'Université L-4365

Esch-sur-Alzette Luxembourg 
continuities and discontinuities in the process of acquiring HE degrees - are an underresearched issue. Despite agreeing that HE is a crucial educational stage for individual and societal development, researchers' interest has also centred on narrow conceptions of dropout and/or (long) study durations (Melguizo 2011), neglecting the fact that students may leave HE, transfer study programmes or HE institutions, interrupt their studies or slow down the pace of study. Data availability, particularly with regard to longitudinal student data, may be one reason for this. Trajectories not only deserve more attention as more data become available, but obviously, the developments of HE during the last 50 years, namely the expansion, diversification (Schofer and Meyer 2005) and heterogenisation of student populations due to facilitated access for under-represented social groups (cf. Ayalon et al. 2008; Hadjar and Becker 2009), motivate longitudinal studies on trajectories. The diversity that is increasing with regard to HE institutions and pathways, as well as with regard to the student population, comes along with a diversification of trajectories. An adequate analysis of this diversity involves a longitudinal perspective centring on students' HE trajectories. For example, enrolment does not mean degree completion as some potential is lost on the road towards graduation. And only looking at enrolment and completion/dropout does not allow the identification of certain factors within the educational trajectory that may have led to one or the other outcome. Mechanisms behind negative outcomes such as dropout at certain critical moments occurring between year 1 in HE and the final year (Webb and Cotton 2019) cannot be identified. Although an increasing number of $\mathrm{HE}$ researchers perceive variable-centred and single-institution approaches to research on dropout as too narrow to encompass the complex nature of how students proceed through HE today, trajectory research remains scant (e.g. Andrews et al. 2014; Bahr 2013; Marti 2008). However, there is a slowly increasing interest in trajectories in relation to phenomena such as high dropout rates and long study durations as continuously experienced by many HE systems. Particularly since the publication of major articles and reports on students' trajectories through American HE, the ways in which students proceed through HE have gained some recognition specifically in the US context (Adelman 1999, 2006; Hearn 1992).

While the increasing availability of large-scale longitudinal datasets in many countries now makes it possible to investigate HE trajectories, the approaches seem heterogeneous and limited to their specific country contexts. Therefore, the main aim of this review is to bring together research on trajectories in HE from various country cases, summarizing the big picture of HE trajectory research across specific national HE expertise. This comprises studies on trajectories (rather than on static points in time, such as singular transitions), as they provide a more holistic understanding of certain mechanisms behind educational attainment and inequalities. In addition, we specifically aimed at collecting empirical evidence on $\mathrm{HE}$ trajectories in relation to students' socio-demographic characteristics, including gender, social origin and ethnicity. As the concepts and terms are diverse and our starting point is the question of inequalities in terms of who follows which trajectory and why, we have to limit the scope of our review to research articles that investigate how students proceed through HE from a longitudinal/processual perspective using quantitative, large-scale panel data. Although of no less importance, theoretical as well as qualitative contributions to the courses of students' studies (Ashwin et al. 2014, 2016) — as we will justify below_are not part of this research review. Furthermore, the key aspect is on students' paths through HE - in the literature mainly referred to as students' trajectories, paths or pathways through HE (as we will describe further below) - i.e. on their enrolment or progress patterns rather than in relation to students' cognitive development, well-being, sense of belonging or processes of integration in HE. 
Our review follows common methodologies (cf. Andrews 2005), encompassing a summary of existing knowledge, synthesis of results and identification of knowledge gaps. While systematic reviews are seldom conducted in HE research (Bearman et al. 2012), our review includes studies on HE trajectories that follow students over a long time period. In attempting to provide a holistic picture by including studies from a wide range of countries and quantitative research designs, we consider two broad issues: (a) how trajectories through $\mathrm{HE}$ are reconstructed, including major definitions, theoretical frameworks regarding macro-, meso- and micro-level impacts and linkages between these levels of sociological inquiry, and the methodological designs in terms of how the dynamic approach is applied, and (b) who follows which HE trajectory and why, including a summary of major empirical findings and mechanisms. Furthermore, we focus specifically on major dimensions of (historically) disadvantaged groups as HE success is globally still characterized by unequal opportunities in major categories such as gender, social origin and ethnicity. In the final section of this paper, we will present the major implications for research on students' trajectories, as one of the main purposes of this paper is the systematization of existing research and pointing out existing knowledge gaps.

\section{Review strategy}

In an attempt to link a systematic review methodology with a broad overview of concepts, data types and regional focus, we opted for a narrative review with systematic elements (Suri and Clarke 2009). This approach has two advantages: we base our review on a set of inclusion/ exclusion criteria but go beyond descriptive approaches based on counting indicators and exploit the articles in more depth regarding theoretical frameworks, methodologies and empirical findings.

As a quality criterion, we restricted our research to peer-reviewed journal articles. First, we searched Web of Science and the Education Resources Information Center (ERIC) for specific terms in the article titles and manually checked studies for suitable content based on their titles and abstracts. ${ }^{1}$ Second, we checked the most relevant HE journals by screening their titles and abstracts, including Research in Higher Education, Journal of Higher Education, Higher Education, Review of Higher Education and Studies in Higher Education. Finally, we applied a snowball approach, i.e. we included studies cited in other articles that suited our search criteria.

\footnotetext{
${ }^{1}$ In Web of Science and ERIC, we searched articles that included at least one of the terms higher education, college, postsecondary, tertiary, student(s), university/ies, as well at least one of the terms pattern(s), pathway(s), trajectory/ies, path $(s)$, career $(s)$, denoted by the following search commands:
}

- Web of Science: $(\mathrm{TI}=$ ("higher education" OR college* OR postsecondary OR tertiary OR student* OR universit*) AND TI $=($ Pattern* OR pathway* OR trajector* OR path* OR career*)) AND DOCUMENT TYPES: (Article)

- ERIC: title:(Pattern OR patterns OR pathway OR pathways OR trajectory OR trajectories OR path OR paths) AND ("higher education" OR college OR postsecondary OR tertiary OR student OR university)

The search results were refined by years of publication and in ERIC also by journal article and by discipline. We could not use Scopus as its search functions do not permit the narrowing of search results by discipline. 
The following criteria have been applied: articles in English published in peer-reviewed journals during the last two decades (1999-2018). We then restricted the sample to empirical articles with a quantitative research focus using panel data and that focused on trajectories as a longitudinal concept, for example studies that investigated enrolment patterns from first-time enrolment until graduation. Accordingly, studies were excluded if they focused only on the occurrence of single events within the trajectory (dropout, transfer), or on the transition into HE or from HE into the labour market. Furthermore, we excluded studies that focused on specific student populations as well as intervention studies, for example on the long-term effect of remediation, as well as those that investigated the longitudinal development of learning patterns, grades or psychological constructs along the HE trajectories. Finally, we sought studies covering a reasonably long time span, i.e. which enabled observation of trajectories ideally from enrolment to degree completion. Hence, studies focusing on first-year outcomes were excluded.

After identifying all the articles for the research review, we coded them by research question, theoretical focus, research design, data and geographical and time focus. After a revision of the original sample, a subsample of 27 articles was retained.

\section{Overview of the literature review sample}

The review comprises 27 studies from 14 different journals, indicating the diversity of our sample. Eight articles were published in Research in Higher Education, followed by Higher Education and Studies in Higher Education with three publications each, making these the three most important sources on trajectories in HE.

With regard to the time span, we considered articles published during the last two decades. From our small sample, it seems that scholarly interest in HE trajectories has risen over the years: only six publications date back to the period 1999-2008, while 21 publications were published between 2009 and 2018.

While 18 articles focus on students' trajectories in the United States (USA), a smaller proportion of articles cover HE trajectories in Australia, Canada, Italy, New Zealand, South Africa and Spain (Table 1).

These figures are in line with the finding of Tight (2018) that most studies on students' experiences in HE come from the USA, where the field is more established than elsewhere. As the HE system in the USA was the first to experience expansion and massification, there was an early interest in, and need for, research on students' experiences, thereby leading to a long tradition of study in the field and expertise in exploiting large-scale panel data on students (Renn et al. 2014). In contrast, the lack of studies from Asia mirrors the general state of Asian HE research in the international context (Horta 2018).

Table 1 Country focus of reviewed studies

\begin{tabular}{ll}
\hline Region: country (number of studies) & Studies \\
\hline Africa: South Africa (2) & 2 \\
Europe: Italy (2), Spain (1) & 3 \\
North America: Canada (1), USA (18) & 19 \\
Oceania: Australia (1), New Zealand (2) & 3 \\
Total & 27 \\
\hline
\end{tabular}




\section{Review results: an overview of the state of research on students' trajectories in higher education}

In this section, we present an overview in four sections: definition, theoretical approach, research design and empirical findings.

\section{Definitions and conceptions: what are trajectories in higher education?}

Throughout the articles, various terms are used to describe how students proceed through HE: authors often used terms such as pathway, trajectory, path, student progression and postsecondary career interchangeably and without any clear notion about what distinguishes these terms from each other. Some used them to describe enrolment patterns in terms of enrolment intensity or continuity while other authors referred to institutional transfer patterns or specific course-taking patterns. However, the term trajectory was more often used in contexts in which nuanced course-taking patterns are analysed, while pathways seemed to refer to broader educational categories such as type of HE institution or programme type enrolled for.

Referring to Elder's (Elder 1985 classic work on the life course paradigm, Pallas (2003, 168) defined pathways as "well-travelled sequences of transitions that are shaped by cultural and structural forces"; in contrast, using the example of employment careers, trajectories are defined as an "individual's sequence of jobs held across the socioeconomic life cycle" (Pallas 2003, 167). Hence, while both trajectories and pathways consist of sequences of transitions and states, "a trajectory is an attribute of an individual, whereas a pathway is an attribute of a social system" (Pallas 2003, 167). Thus, the former refers to an outcome resulting from individual circumstances and preferences, while the latter describes systematic patterns that result from individual choices but acknowledges that these are shaped by particular constraints and opportunities. In this regard, Pallas (2003) referred particularly to the features of education systems, but one might also think of labour markets, welfare states, norms and societal expectations, such as those regarding age or gender.

In considering these definitions, we prefer the term "trajectory" to refer to actual progression through $\mathrm{HE}$ - and thus empirical student experiences-including all transitions (e.g. from undergraduate to graduate studies) and states (e.g. enrolment patterns such as part-time vs full-time enrolment) within a certain period (e.g. academic year or 3-year life period; Sackmann and Wingens 2001, 42), while we assign the term "pathway" to institutionally ideal progression patterns. The ideal pathway in terms of a norm implicitly or explicitly related to is that of full-time students who directly transit from secondary school to HE and study for the regular study duration of 3 or 4 years. Here, an important distinction relates to traditional vs non-traditional trajectories (or, as used synonymously, pathways). In terms of institutionalized pathways, traditional pathways are marked by immediate transitions between high school and $\mathrm{HE}$ and continuous full-time enrolment in a 4-year institution, while non-traditional pathways are characterized by delayed transitions into $\mathrm{HE}$, interruptions, high work intensity or studies at a research university (e.g. Andrews et al. 2014). 


\section{Theories: which conceptual approaches are employed to theorize trajectories?}

Articles whose main interest was in investigating students' motives for specific decisions along their HE trajectories provided extensive theoretical frameworks. In contrast, articles published predominantly in HE journals mainly aimed at describing students' trajectories through HE were of rather applied nature and often lack theoretical frames. In this section, we summarize the theoretical concepts focusing on micro-, meso- and macro-level attributes that shape students' HE trajectories.

\section{The micro-level: students' decision-making processes as the conceptual grounding for higher education trajectories}

A dominant approach framed trajectories in HE as the outcome of educational decisions. In these sociological and economic perspectives, students try to make decisions in their best interest - based on balancing costs and benefits that come along with specific educational routes, tracks or types. Such applications of the classical human capital approach (Becker 1964) have been applied in several of the reviewed papers. For example, Johnson and Muse (2012) perceived students in HE as utility-maximizing agents that are willing to invest in $\mathrm{HE}$ as long as the benefits exceed the costs of it. Kalogrides and Grodsky (2011) perceived students as rational actors that are constrained by imperfect information on HE or their future labour market prospects, which consequently hampers their decision-making. Similarly, Andrews et al. (2014) framed students as actors that constantly update their information on HE prospects and that only decide to transfer from one HE institution to another when they realize that the expected benefits of doing so outweigh the costs.

Educational decisions in general, and decisions on HE specifically (e.g. Becker and Hecken 2009), are often studied in light of rational choice or subjectively expected utility approaches (Becker 2003), assuming that decisions in favour of or against educational institutions or pathways are taken considering the benefits (labour market outcomes, maintenance of family status), costs (direct costs such as study fees, indirect costs such as lost income) and the probability of completing a certain pathway. In addition, Breen and Goldthorpe (1997) advanced this theoretical frame to explain differences in decision-making by social origin. Studies referring to this theoretical framework argued that social origin systematically shapes decision-making in HEeither because of the unequal monetary resources, information asymmetry or differences in educational strategies or of the perception of the benefits of HE. For example, Byun et al. (2017) referred to students' sociocultural and financial resources as a major factor while Goldrick-Rab (2006) and Goldrick-Rab and Pfeffer (2009) stressed differences in students' strategies regarding institutional transfers. They argued that students from advantaged social backgrounds are better equipped in terms of financial resources and information that help them to plan accordingly, to navigate through $\mathrm{HE}$ and to make the right choices within HE from the beginning but also to deal with unforeseen changes along their HE trajectories. Furthermore, they found that such effects are mediated by students' achievement and expectations. 


\section{The micro-level II: higher education trajectories as series of educational decisions and transitions}

In some articles, students' trajectories were conceptualized as a series of decisions that students have to make along their trajectory. Graduation is the final step of a long trajectory of decisions and transitions. Students may leave at various points, but every step needs to be taken in order to reach the next one. This goes back to Mare (1980), who framed educational careers as successive transitions, where the sequential nature of students' HE trajectories is emphasized.

For example, Giani (2015) argued that there might be social origin differences in decisionmaking at each step along their postsecondary trajectory as students differ in terms of their economic and academic resources and the resources provided by the institution. Thus, he investigated seven postsecondary stages: application, acceptance, enrolment, persistence/transfer, attainment, graduate school entry and completion. Milesi (2010) also referred extensively to this approach but stated that an "orderly sequence of irreversible transitions" (27) might not be applicable to adequately depict HE trajectories of today's students anymore as it ignores the use of alternative and non-linear trajectories leading to graduation.

In a similar vein, some studies conceptualized HE trajectories as sequential steps to be made but stressed specific actions to be taken in order to make such choices (Childs et al. 2017; Cosser and Nenweli 2014). Hossler et al.'s (1989) college choice model comprises the formation of college ambitions, planning, admission, enrolling, attending and completing college. Similarly, St. John et al.'s (2001) student choice model includes the following steps: formation of postsecondary and career aspirations, opportunity to attend, college choice, choice and change of major, persistence and graduate education choices. Carbonaro et al. (2011) referred to the college choice model to explain the female advantage in graduation rates. As the cumulated outcome of gender differentials that developed throughout the HE trajectory, they argued that students' choices consist of an extensive (self-)selection process into HE comprising of planning for admission, applying, admission, enrolment and also HE attendance and completion. They proposed three mechanisms in the HE completion pipeline that may explain the female advantage: first, incipient advantage, i.e. women have a stronger tendency to select themselves into $\mathrm{HE}$ as they are better prepared and plan better accordingly; second, cumulative advantage, i.e. females are advantaged at each step within the college pipeline because of their better skill equipment; and third, because of deferred advantage, i.e. there is a female advantage along their HE trajectories, but these gender differences become only relevant at the final step, namely at graduation. While such approaches certainly add to the understanding of HE trajectories, particularly as they perceive attainment as a process that is comprised of several steps and decisions to be made instead of seeing HE enrolment and graduation as isolated events, it seems - as already stressed by Milesi (2010) - that such approaches do not consider alternative or more complex trajectories, the delay of certain steps or re-enrolment at a later point.

\section{The micro-/meso-level link: trajectories as processes of integration into the HE environment}

Another dominant theoretical perspective refers to a lack of students' integration in educational institutions as a major cause of dropout (e.g. Bean and Metzner 1985; Tinto 1975). In contrast to the decision-centred approaches discussed above, these recognize students' embeddedness in the HE environment. In a similar vein, dropout is a long-term process of social and academic 
(dis)integration in HE. Background variables shape initial goals, intentions and commitments regarding both academic issues (e.g. achievement) and social issues (e.g. interactions and relations with fellow students or teachers). These commitments in turn shape institutional experiences, i.e. how academic and social systems are perceived, affecting academic and social integration. Both dimensions of integration shape subsequent goals, intentions, commitments and finally the dropout decision. Applications were provided in Robinson (2004) on reenrolment vs departure, Ewert (2010) on gender differences along the development of HE trajectories, Meggiolaro et al. (2017) and Johnson and Muse (2012).

\section{Macro-meso-micro links: how do macro- and meso-level factors shape individual trajectories?}

Some articles stressed that students' decisions on how they construct their HE trajectories are deeply embedded and subject to their context. This may refer to their environment, including their peers, family context, context of growing up and neighbourhood. In addition, not only may individual experiences matter, but also the organizational structures of the HE institution in which students are embedded (meso-level), or further, the regional or national structure of the HE system (macro-level).

Several studies encompassed some meso-theoretical concepts, i.e. how the organizational context of the HE institutions influences how students proceed through HE (Clerici et al. 2015; Ewert 2010; Giani 2015; Lassibille and Gómez 2009; Kalogrides and Grodsky 2011). For example, Meggiolaro et al. (2017) argued that larger HE institutions provide more and better services to students. Thus, this is beneficial for students' persistence. They also refer to the well-known finding that more selective programmes and institutions also have higher persistence rates.

In addition to the organizational context of the HE institutions, the structure of the HE system as well as that of the education system in general shape students' trajectories. For example, the openness of an educational system affects how large the share of a cohort is that can access HE. Fees and financial aid systems as well as the selectivity of HE, alternative routes and the existence of strong alternatives to HE matter. While the strength of such effects might best be investigated based on cross-country comparative frameworks, we found that

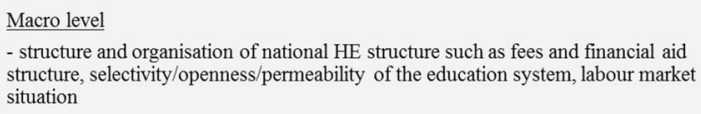

- structure and organisation of national HE structure such as fees and financial aid structure, selectivity/openness/permeability of the education system, labour market situation

\section{Meso level}

- organizational context of the HE institution such as size of programme, level of anonymity, services and mentoring offered, selectivity of study programme, compulsory attendance
Micro level

demographic attributes

information on HE trajectories

individual perception of benefits

costs, risks of educational decisions

Fig. 1 Macro-, meso- and micro-level predictors of HE trajectories ability, academic preparation and academic performance

expectations, motivation, commitment prior educational biography socio-cultural and financial resources
Students'HE trajectories 
such studies were non-existent in HE trajectory research. Yet, some studies provided a conceptual embedding of their national cases in the international landscape (Clerici et al. 2015 on Italy; Lassibille and Gómez 2009 on Spain). For example, Childs et al. (2017) contrasted the Canadian case extensively to the American case. Milesi (2010), who investigated HE trajectories of US American students, described the system as particularly open, less structured and as providing many re-entering options throughout the life course. While this sounds positive, she criticized the fact that such opportunities are not neutral, but that specific groups of students make use of such options and that by following such non-traditional trajectories, they face a higher risk of non-completion.

\section{Research designs: how are higher education trajectories analysed?}

Most studies focused rather generally on students in HE and did not differentiate by field of study, type or level of HE. Some studies specifically looked at trajectories in short-cycle degrees (mostly in US community colleges). In contrast, no study focused specifically on the trajectories of graduate students. In regard to data sources, the majority of studies used national representative large-scale data (15 studies). Four used regional, i.e. state-level, data, while eight studies drew on data from local sources, i.e. data from specific HE institutions.

In what follows, we describe three distinct analytical approaches to how HE trajectories have been operationalized and investigated (cf. Figs. 1 and 2). While the aim of the research papers of the first set was focused on providing a description of $\mathrm{HE}$ trajectory types and patterns, articles in the second and third set of articles were clearly aimed at answering specific questions in relation to students' attributes and centring on the questions of who follows which trajectories and why. However, articles in the second group of articles reconstructed HE trajectories as a holistic concept, differentiating HE trajectories based on specific HE attributes such as interruptions or transfers. In contrast, research designs in the last group reconstructed HE trajectories as successive transitions and decisions.

\section{Describing and reconstructing trajectories}

Eleven studies described students' HE trajectories, but based on very different trajectory characteristics, research designs and data sources. Nonetheless, they were all exploratory in nature and were aimed at identifying common trajectory patterns.

Several articles reconstructed HE trajectories as students' broad, semester-wise or year-wise enrolment patterns: Cosser and Nenweli (2014) combined students' pre-enrolment preferences, actual field of study enrolment and field of graduation into six distinct trajectory patterns. McCormick (2003) investigated the number of HE institutions students enrol at along their HE trajectory. Robinson (2004) and Cosser (2018) used coding systems of the enrolment status at every semester, including persisting, repeating, interrupting, incoming, programme change/ transfer, dropping out and completing. Bach et al. (2000) focused on enrolment patterns distinguishing HE institutions enrolled at, whereas Marti (2008), Noy and Zeidenberg (2017), Robinson (2004), Cosser (2018) and Crosta (2014) made use of semester-wise enrolment patterns such as non-enrolment, part-time and full-time enrolment. As an exemplary outcome, Marti (2008) identified five different trajectory types that differed by length of enrolment and enrolment intensity. 


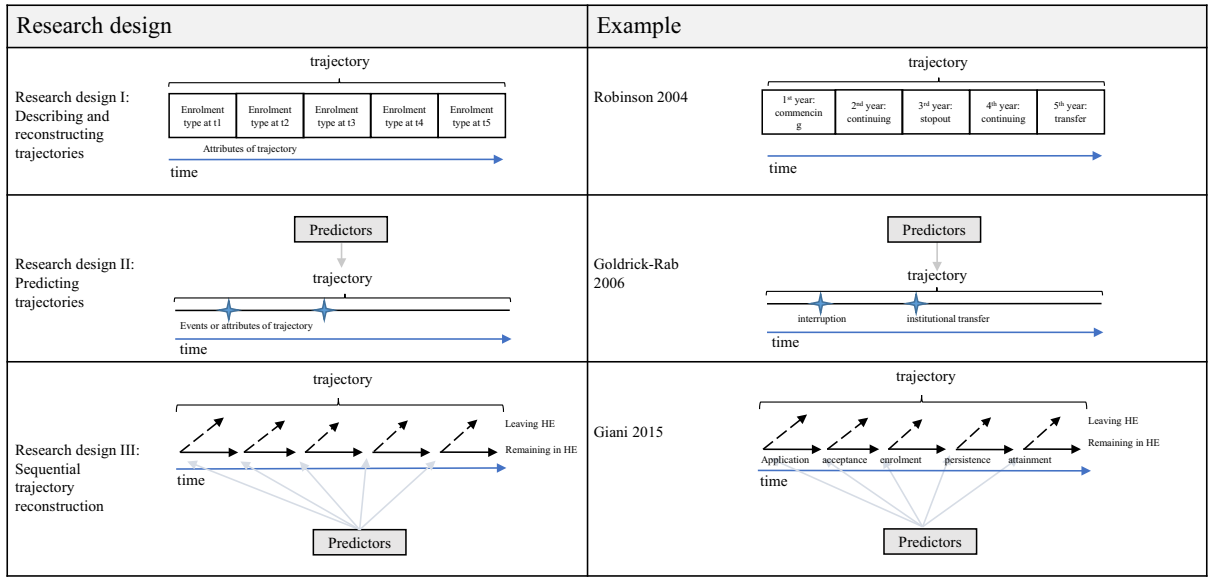

Fig. 2 Research designs with examples

In contrast, specifically when it comes to shedding light on the question of which community college trajectories are beneficial for upward transfer to a research university in the USA, authors used data on course units and course characteristics (Bahr 2010; Bahr et al. 2017; Wang 2016). To do so, they made use of fine-grained data on course characteristics, such as whether courses count as transferable or non-transferable courses, maths course credits, course level or the number of attempts needed to complete a course. Then, they used various techniques to cluster those trajectory patterns.

\section{Predicting trajectories}

Another set of papers tried to explicitly focus on trajectory prediction, i.e. in addition to categorizing and describing trajectory patterns, researchers also investigated what characteristics make students particularly more likely to follow specific trajectories.

Predominant in this category was the use of various regression and event history analysis techniques. In the first case, several categories of students' HE trajectories were constructed based on one or several trajectory characteristics, such as enrolment intensity (part-time vs full-time enrolment; Ewert 2010), (dis-)continuity of enrolment (interruptions vs no interruptions; Ewert 2010; Goldrick-Rab 2006), trajectory outcomes (persistence vs dropout; Kalogrides and Grodsky 2011; Childs et al. 2017) or transfer between HE institutions (Goldrick-Rab 2006; Childs et al. 2017). Transfer was even further distinguished into lateral or reverse transfer (Goldrick-Rab and Pfeffer 2009; Kalogrides and Grodsky 2011; Byun et al. 2017). In a second step, binary or multinomial logistic regression was used to predict which demographic characteristics, prior educational pathways or educational achievement enable or hamper specific trajectories through HE.

In the second case, authors used models that explicitly take time to event occurrence into account, such as competing risk discrete-time event history analysis (Clerici et al. 2015; Meggiolaro et al. 2017; Lassibille and Gómez 2009) or multilevel discrete-time logit models (Johnson and Muse 2012). In addition to the previously mentioned approaches, these captured a time component by not only looking at which specific trajectory type students follow, but also when events within a HE trajectory occur. In the same vein, the papers by Clerici et al. 
(2015), Meggiolaro et al. (2015) and Lassibille and Gómez (2009) considered trajectories by whether and when students change their studies, delay, drop out or graduate while Johnson and Muse (2012) investigated the timely occurrence of enrolment and re-enrolment after initially leaving HE.

\section{Sequential trajectory reconstruction}

Lastly, a few papers also applied an educational transition model perspective. This cluster comprises articles that address how students make progress and proceed through HE. Such research designs are closely linked to the theoretical conception of trajectories as sequential decisions. Therefore, sequential binomial or multinomial logistic regression models were predominant. Students' continuation decisions were predicted against a set of other outcome options successively over the course of their studies. Studies conceptualized trajectories as successive continuation vs non-continuation decisions at various time points. For example, continuation vs leaving decisions (vs completion during the last year) were predicted for each academic year, conditional on completing the previous year (Shulruf et al. 2010; Tumen et al. 2008).

Similar studies, but in the tradition of Manski and Wise (1983) and Hossler et al. (1989), focused on sequences of student decisions other than yearly or semester-wise re-enrolment (Carbonaro et al. 2011; Giani 2015). For example, Carbonaro et al. (2011) examined gender differences along the college pipeline, finding persisting advantages for females along almost all transitions. The relatively recent study by Giani (2015) provided a very comprehensive approach regarding sequential progression through $\mathrm{HE}$ by analysing seven stages using logistic regression: application, acceptance, enrolment, persistence, attainment, graduate school entry and completion.

\section{Empirical findings: who follows which trajectory and why?}

Within this section, we summarize some major empirical findings on the relationship between students' socio-demographic characteristics, namely gender, social origin and ethnicity, and the HE trajectory followed. While this is certainly a condensed extract of all findings, we chose those categories as they reflect the main interest of many articles across a range of different research designs. As the studies varied by data type - ranging from administrative data with limited information on student characteristics to data with rich background information - and analytical strategy-descriptive bivariate techniques as well as multivariate research techniques - it is difficult to compare empirical findings from different studies. Furthermore, some studies are based on small or single-institution samples; thus, generalizations should be made with caution.

The major part (20 articles) of the review sample did not focus on specific sociodemographic characteristics as a major theme of their article. Among those that did so, four focused specifically on students' social origin, two focused on students' gender and one study specifically looked at students from rural areas. None of the studies specifically focused on students' ethnicity, even though this was often a theme in the empirical findings. Yet, differences in students' HE trajectories by social origin, gender or ethnicity were addressed in many articles. 
However, as Table 2 shows, the studies based on survey data pointed to the fact that both gender and social origin differences in HE trajectories are likely explainable with reference to differences in prior schooling trajectories, preparation for $\mathrm{HE}$ and prior or current academic achievement.

\section{Differences in HE trajectories by gender}

Two articles specifically focused on gender differences in HE trajectories (Ewert 2010; Carbonaro et al. 2011). Ewert (2010) investigated gender differences among students enrolled at 4-year institutions as an explanation for the growing gender gap in US graduation rates. Operationalizing HE trajectories as a categorical variable, she found that women are indeed more likely to follow full-time continuous HE trajectories. In a second step, she gradually added more explanatory variables to her model, finding that the gender difference in $\mathrm{HE}$ trajectories can be partly explained with reference to academic performance and preparation. This was in line with Carbonaro et al.'s (2011) findings. In their sequence of educational transitions through HE, they also identified a female advantage in graduation rates if women enrol for a 4-year institution, but on the other hand, women are less likely to continue their HE trajectory at a 4-year institution if they decide to enrol at a 2-year institution after high school.

Overall, studies seemed to be conclusive that male students are more likely to follow discontinuous and less stable trajectories. In line with Ewert's (2010) study, Goldrick-Rab (2006) found that women in the USA have a lower proportion in HE trajectories that are characterized by interruptions. Other studies focusing on Italian, New Zealand, Spanish and US HE found that male students are over-represented in non-completion, transfer and/or delayed trajectories (Clerici et al. 2015; Kalogrides and Grodsky 2011; Lassibille and Gómez 2009; Meggiolaro et al. 2017; Shulruf et al. 2010).

Yet, there were also studies that found no gender differences (Goldrick-Rab and Pfeffer 2009; Tumen et al. 2008) in students' progression and transfer patterns and studies that employed multivariate modelling in which no remaining net effect of gender was found (Byun et al. 2017).

Focusing specifically on course-taking patterns of students at US community colleges, Bahr (Bahr 2010; Bahr et al. 2017) found on the one hand that male students were over-represented in the non-credit trajectory cluster, but on the other hand, looking specifically at trajectories in STEM fields, that course-taking patterns differ systematically by gender: female students take lower-level courses and stop their STEM course career earlier than men-pointing on the one hand to the significance of the prior schooling trajectory, but on the other also to the contradictory findings on gender differences in HE trajectories depending on which specific part of the trajectory is investigated.

\section{Differences in HE trajectories by social origin}

Several articles focused on the effects of students' social origin on trajectories followed. Specifically, studies from the USA found that students from low social origin follow less often smooth trajectories through HE: students from low social origin have more interruptions and more reverse transfers (transfer from 4-year institution to 2-year institution; Byun et al. 2017; Ewert 2010; Goldrick-Rab 2006; Goldrick-Rab and Pfeffer 2009; Kalogrides and Grodsky 2011; Milesi 2010), while students from high social origin more often engage in smooth 4-year trajectories and lateral transfer trajectories (transfer from four-year to four-year 


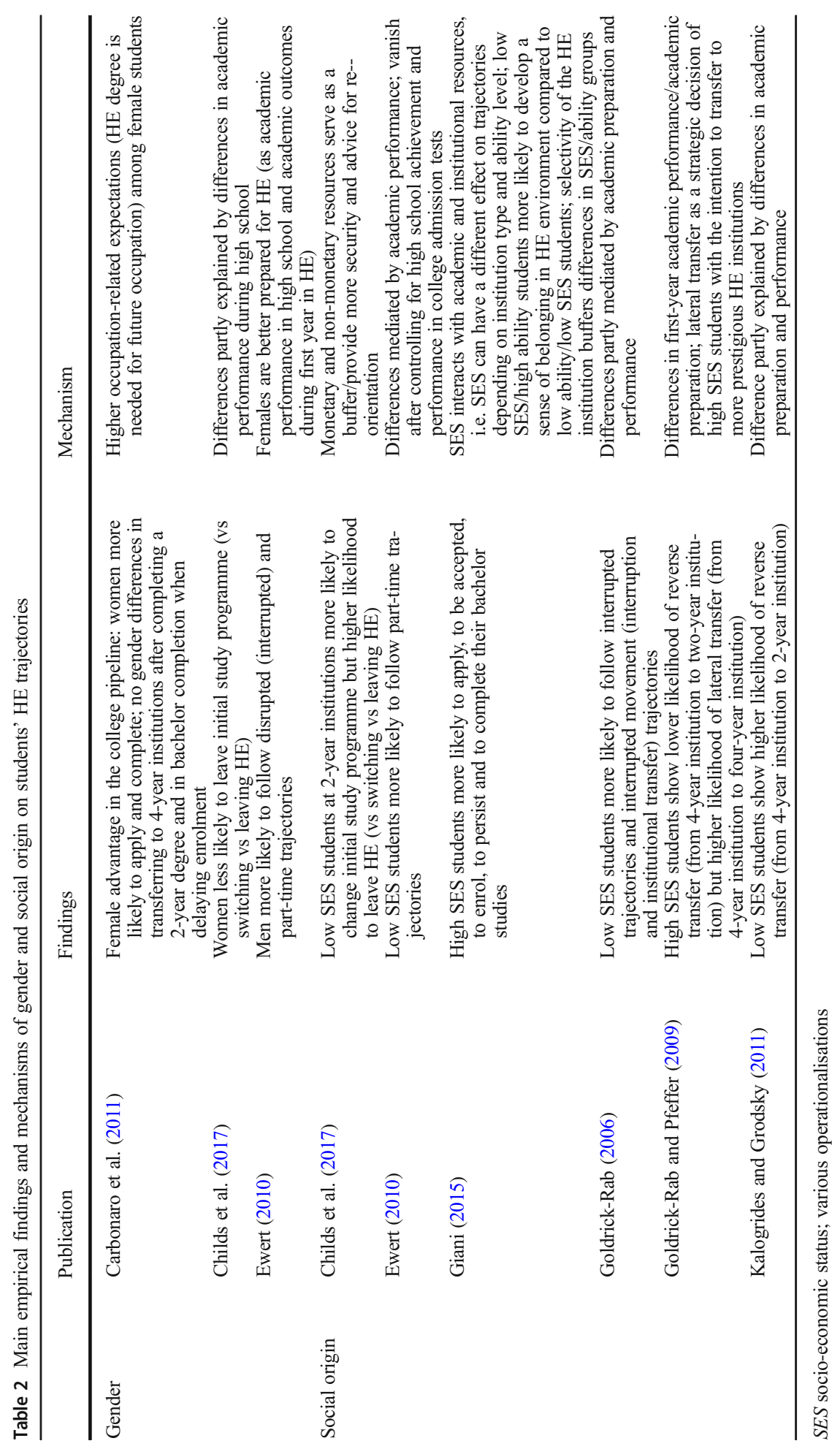


institution; Goldrick-Rab and Pfeffer 2009; Kalogrides and Grodsky 2011). As for gender effects, Goldrick-Rab and Pfeffer (2009) found that social origin differences in lateral and reverse transfer in HE trajectories could be explained by differences in academic preparation and performance indicators, while social origin differences in interruptions persisted even after controlling for various other factors (Goldrick-Rab 2006). In line with the US findings, Lassibille and Gómez (2009) found for Spain that students from high social origin were over-represented in transfer trajectories, but that these effects could largely be explained with reference to their prior educational pathways.

While Childs et al. (2017) found that students of high social origin were less likely to drop out and more likely to transfer at Canadian community colleges, they also found that university students from low social origin were actually more likely to persist in HE after controlling for a wide range of factors - perhaps pointing to the fact that university students from low social origin depict a specific group in terms of their motivation or ambition.

In their models already controlling for a wide range of factors, Tumen et al. (2008) and Shulruf et al. (2010) did not find any remaining significant social origin effect for New Zealand students. Focusing on South Africa, Cosser (2018) found that students of high social origin changed more often their original programme and also that these students had a lower incidence of dropout but higher completion rates. Yet, this approach was rather descriptive and did not control for other student characteristics.

\section{Differences in HE trajectories by ethnicity}

Although none of the articles looked specifically at ethnicity - to be more precise, this encompasses also nationality and race - and underlying mechanisms to explain such differences, these attributes were considered in many studies. Despite differences in data type and study design, findings regarding HE trajectories resembled each other across countries: historically disadvantaged groups follow less continuous and stable trajectories.

For example, US studies found that Black, Hispanic and American Indian students have more dropouts, interruptions and reverse transfers along their HE trajectories while White students are over-represented in lateral transfer trajectories and stable 4-year persistence trajectories (Goldrick-Rab 2006; Ewert 2010; Kalogrides and Grodsky 2011). For New Zealand, Shulruf et al. (2010) found that students of European origin had a lower likelihood of in-time graduation, while, focusing on Canada, Childs et al. (2017) found that students of aboriginal origin faced a higher dropout risk. Considering students' nationality in Italian HE, Meggiolaro et al. (2017) and Clerici et al. (2015) observed that foreign students were more likely to follow dropout, programme change and delayed completion trajectories. As for gender and social origin, several multivariate analyses showed that these effects can be explained by students' performance and pre-HE educational trajectories (Byun et al. 2017; Childs et al. 2017; Goldrick-Rab 2006; Goldrick-Rab and Pfeffer 2009; Kalogrides and Grodsky 2011).

\section{Conclusions and implications}

In contrast to the extensive literature on student behaviour in HE such as on dropout, research on students' HE trajectories is a rather small, fragmented and heterogeneous field. Therefore, this review aimed to provide a comprehensive overview of the latest significant conceptual and 
methodological approaches to examining students' trajectories in HE from various country contexts. To grasp the various approaches adopted in exploring students' trajectories during the last two decades, we based our review on a rather broad conception, by not only including articles that explicitly included the terms "pathway" or "trajectory" in their titles but also studies that looked longitudinally at enrolment patterns or educational transitions in HE with an explicit focus on timing or duration.

Our review sample shows that research with a geographic focus on the USA dominates research on students' trajectories in HE - a finding that might be explained with reference to the USA's early HE expansion and diversification and its consequential pioneering role in collecting large-scale longitudinal data on students.

In terms of the limitations of our methodology, this review may be subject to selection bias as we only considered journal publications. This was due to a trade-off ensuring a certain research standard. The wide range of research designs and data hampers the application of a more systematic, meta-analytical review method. As we had to reduce the level of complexity, we restricted our focus to studies using quantitative research designs based on longitudinal data. However, theoretical works (Robinson and Bornholt 2007) and qualitative studies (such as the works of Ashwin et al. 2016; Bensimon and Dowd 2009; Christie et al. 2016; Harper 2007; Tett et al. 2017) focusing on reconstructing students' motives and reflections on their choices made along their HE trajectories did not gain the attention they deserve, as they bring to light even more subjective reasonings of the students that may go beyond the conceptual lenses of the quantitative researchers.

With regard to theoretical frames, despite a vast number of studies that omit an explicit conceptual framework, the results revealed a dominance of theories centring on students' decision-making processes. Surprisingly, theories predominantly employed in dropout research, such as Tinto's (1975) student integration model, were not that often discussed, although HE research scholars had already tried to integrate these two theoretical lines (Beekhoven et al. 2002).

Furthermore, we identified and distinguished three broad analytic strategies ranging from approaches aimed at describing students' trajectories to studies in which HE trajectory types are predicted to studies conceptualizing HE trajectories as sequential transitions. Against this background, the heterogeneity of research designs makes the comparison and the integration of results difficult. The main outcomes can be summarized as follows: looking at HE trajectories in terms of broader enrolment patterns confirmed the female advantage along HE trajectories. Yet, when looking at more fine-grained aspects such as community college course-taking patterns in STEM fields, course-taking patterns shaped by traditional gender orientations could be found. In contrast, studies from various country backgrounds are conclusive that students' social and ethnic origin affects trajectories through HE such that students from lower social origin or from historically disadvantaged groups are more likely to follow non-linear and unstable HE trajectories. In addition, these findings were often attributable to students' prior educational biography, preparation for HE and achievement, pointing to the fact that such outcomes may have their origin much earlier in the educational trajectory. This has severe implications given the fact that following non-traditional trajectories is strongly related to $\mathrm{HE}$ non-completion (Milesi 2010).

The results of the review allow the deduction of certain implications and directions for further research: first, as we intended to place an emphasis on theories framing students' trajectories in HE, we noted that several studies seemed to be rather data driven and lack conceptual frames, building their argument upon prior empirical findings (see Kuh et al. 1986). 
This finding parallels Tight's (2004) conclusion that HE researchers, "for the most part, do not appear to feel the need to make their theoretical perspectives explicit or to engage in a broader sense in theoretical debate" (409). Therefore, we would like to stress the conceptual parallels between life course sociology and research on trajectories in (higher) education and hence emphasize the usefulness of the life course concept as a heuristic toolbox for researching students' trajectories in HE. As Crosnoe and Benner $(2016,179)$ noted, life course sociology has become an integral part of the sociology of education, acknowledging that "the educational career is a transition-rich long-term trajectory within a highly structured institutional system" that is shaped by micro-, meso- and macro-level processes.

Second, while macro-micro links, such as the research issue of how educational systems shape educational opportunities and schooling careers, have been widely researched regarding other educational levels or transitions, for example at the transition from primary to secondary education, secondary schooling or school-to-work transitions (Hadjar and Gross 2016; Kerckhoff 2001), these have not been widely adopted in HE research (exceptions: Shavit et al. 2007; Reisel and Brekke 2009). Indeed, the majority of studies on HE trajectories covered in this review have focused on individual-level predictors (e.g. socio-demographic characteristics, prior educational biography, achievement) and a few have attempted to shed light on the meso-level effects of organizations (e.g. the structure of study programmes). Missing is a focus on how national HE systems and HE institutions affect HE trajectories on the micro-level, i.e. how the opportunity structures they provide affect decisions of different student groups along their HE trajectories (for an exception, see Giani 2015). In this vein, some qualitative works point to the difficult interplay of structural constraints and individual opportunities (Baker 2019; Bensimon and Dowd 2009).

There may be several reasons for this lack of attention. Reale (2014) pointed to the challenges of comparative research designs (see also Brennan and Teichler 2008; Kosmützky and Krücken 2014). Furthermore, HE expansion, massification and differentiation led to an early focus on the increasing complexity and variability of students' trajectories in the USA. This high research concentration led to an inward-looking perspective on HE in the USA, in which reflections at the system level seemed not so relevant or taken for granted (Tight 2018). In sum, embedding students' trajectories in a wider context of the structures of the HE system would improve our understanding of long-term student behaviour in light of the opportunities and constraints that the HE system of a specific country context provides. The field of HE research may certainly benefit — both conceptually and empirically - from a stronger focus on comparative research (Renn et al. 2014). As increasing numbers of countries are conducting large-scale (panel) studies on students, there is also growing potential for comparative research on students' experiences and trajectories in HE.

Third, the set of studies reviewed included very diverse methodological approaches: some studies developed very fine-grained typologies of students' HE trajectories based on register/ administrative data while other studies were based on survey data. Clearly, the data types constrain the set of research questions one is able to answer. While the former provides indepth knowledge about students' actual course-taking behaviour and detailed routes through $\mathrm{HE}$, such studies are restricted regarding reasons why students follow the trajectories they opted for. In contrast, the latter, survey-based approaches are limited to a set of predefined variables to reconstruct students' HE trajectories but are more flexible in linking these to students' prior educational biographies, motives and social origin. In the same vein, we also see great potential for understanding the circumstances and motivation that lead students to follow specific trajectories in theory-led mixed methods or qualitative studies - a claim that 
has already been raised elsewhere (Harper 2007; Rodríguez-Gómez et al. 2016): "[A]s long as student behaviour remains a proverbial black box, institutional adjustments and interventions will be more a product of guesswork than of sound and empirically based reasoning" (Bahr 2013, 144).

The relevance of students' trajectories in HE, enrolment patterns and how students proceed through HE as a theme constitutes an important future research programme, especially as "completion of any four-year degree is likely a watershed event in individual biographies" (Stevens et al. 2008, 131). The end of HE expansion is out of sight, with especially the group of non-traditional students-first-generation students (i.e. the first generation in a family participating in HE), students who combine employment or family duties and HE or students with alternative access qualifications-being on the rise. Hence, it is vital to gain more systematic knowledge regarding who proceeds and how through HE and with what consequences. This knowledge may help deprived groups in the HE system to improve their chances of completing their studies successfully by identifying critical factors, moments and mechanisms such as behind "sophomore slumps" (Webb and Cotton 2019).

With regard to practical implications, the findings of empirical research so far point to the crucial relationship between upper-secondary schooling and higher education: Schools and higher-education institutions need to detect lack of achievement at early stages and provide resources to close these. Furthermore, comprehensive information provided through mentoring, guidance and counselling on opportunities and demands - given before and after HE enrolment - appears to be essential for successful trajectories (Crisp et al. 2009; Baker 2019). Lack of commitment and motivation could be addressed by integrating measures linked to social and academic integration (e.g., providing opportunities to improve student-student and student-teacher contacts, smaller study groups). On the education system level providing resources, and thus, a strong financial base and a focus on international differentiationcompensating for lack of resources among certain student groups such as working class or male students - rather than external differentiation and the provision of highly selective homogeneous institutions.

\section{Compliance with ethical standards}

Conflict of interest The authors declare that they have no conflict of interest.

Open Access This article is distributed under the terms of the Creative Commons Attribution 4.0 International License (http://creativecommons.org/licenses/by/4.0/), which permits unrestricted use, distribution, and reproduction in any medium, provided you give appropriate credit to the original author(s) and the source, provide a link to the Creative Commons license, and indicate if changes were made.

\section{References}

(*) reviewed paper

Adelman, C. (1999). Answers in the toolbox: academic intensity, attendance patterns, and bachelor's degree attainment. Washington, DC: U.S. Department of Education. 
Adelman, C. (2006). The toolbox revisited: paths to degree completion from high school through college. Washington, DC: U.S. Department of Education.

Andrews, R. (2005). The place of systematic reviews in education research. British Journal of Educational Studies, 53(4), 399-416.

*Andrews, R., Li, J., \& Lovenheim, M. F. (2014). Heterogeneous paths through college: detailed patterns and relationships with graduation and earnings. Economics of Education Review, 42, 93-108.

Ashwin, P., Abbas, A., \& McLean, M. (2014). How do students' accounts of sociology change over the course of their undergraduate degrees? Higher Education, 67(2), 219-234.

Ashwin, P., Abbas, A., \& McLean, M. (2016). Conceptualising transformative undergraduate experiences: a phenomenographic exploration of students' personal projects. British Educational Research Journal, 42(6), 962-977.

Ayalon, H., Grodsky, E., Gamoran, A., \& Yogev, A. (2008). Diversification and inequality in higher education: a comparison of Israel and the United States. Sociology of Education, 81(3), 211-241.

*Bach, S. K., Banks, M. T., Kinnick, M. K., Ricks, M. F., Stoering, J. M., \& Walleri, R. D. (2000). Student attendance patterns and performance in an urban postsecondary environment Research in Higher Education, 41(3), 315-330.

*Bahr, P. R. (2010). The bird's eye view of community colleges: a behavioral typology of first-time students based on cluster analytic classification. Research in Higher Education, 51(8), 724-749.

Bahr, P. R. (2013). The deconstructive approach to understanding community college students' pathways and outcomes. Community College Review, 41(2), 137-153.

*Bahr, P. R., Jackson, G., McNaughtan, J., Oster, M., \& Gross, J. (2017). Unrealized potential: community college pathways to STEM baccalaureate degrees. The Journal of Higher Education, 88(3), 430-478.

Baker, Z. (2019). Reflexivity, structure and agency: using reflexivity to understand further education students' higher education decision-making and choices. British Journal of Sociology of Education, 40(1), 1-16.

Bean, J. P., \& Metzner, B. S. (1985). A conceptual model of nontraditional undergraduate student attrition. Review of Educational Research, 55(4), 485-540.

Bearman, M., Smith, C. D., Carbone, A., Slade, S., Baik, C., Hughes-Warrington, M., \& Neumann, D. L. (2012). Systematic review methodology in higher education. Higher Education Research \& Development, 31(5), 625-640.

Becker, G. S. (1964). Human capital: a theoretical and empirical analysis, with special reference to education. New York: National Bureau of Economics.

Becker, R. (2003). Educational expansion and persistent inequalities of education: utilizing subjective expected utility theory to explain increasing participation rates in upper secondary school in the Federal Republic of Germany. European Sociological Review, 19(1), 1-24.

Becker, R., \& Hecken, A. E. (2009). Higher education or vocational training? An empirical test of the rational action model of educational choices suggested by Breen and Goldthorpe and Esser. Acta Sociologica, 52(1), $25-45$.

Beekhoven, S., de Jong, U., \& van Hout, H. (2002). Explaining academic progress via combining concepts of integration theory and rational choice theory. Research in Higher Education, 43(5), 577-600.

Bensimon, E. M., \& Dowd, A. (2009). Dimensions of the transfer choice gap: experiences of Latina and Latino students who navigated transfer pathways. Harvard Educational Review, 79(4), 632-659.

Breen, R., \& Goldthorpe, J. H. (1997). Explaining educational differentials: towards a formal rational action theory. Rationality and Society, 9(3), 275-305.

Brennan, J., \& Teichler, U. (2008). The future of higher education and of higher education research. Higher Education, 56(3), 259-264.

*Byun, S.-Y., Meece, J. L., \& Agger, C. A. (2017). Predictors of college attendance patterns of rural youth. Research in Higher Education, 58(8), 817-842.

*Carbonaro, W., Ellison, B. J., \& Covay, E. (2011). Gender inequalities in the college pipeline. Social Science Research, 40(1), 120-135.

*Childs, S. E., Finnie, R., \& Martinello, F. (2017). Postsecondary student persistence and pathways: evidence from the YITS-A in Canada. Research in Higher Education, 58(3), 270-294.

Christie, H., Tett, L., Cree, V. E., \& McCune, V. (2016). 'It all just clicked': a longitudinal perspective on transitions within university. Studies in Higher Education, 41(3), 478-490.

*Clerici, R., Giraldo, A., \& Meggiolaro, S. (2015). The determinants of academic outcomes in a competing risks approach: Evidence from Italy. Studies in Higher Education, 40(9), 1535-1549.

*Cosser, M. (2018). Differential pathways of South African students through higher education. International Journal of Educational Development, 59, 100-109.

*Cosser, M., \& Nenweli, S. (2014). "We've got you pegged": programme choice in the transition to, and passage through, higher education. Higher Education, 67(3), 333-348. 
Crisp, G., Nora, A., \& Taggart, A. (2009). Student characteristics, pre-college, college, and environmental factors as predictors of majoring in and earning a STEM degree: an analysis of students attending a Hispanic serving institution. American Educational Research Journal, 46(4), 924-942.

Crosnoe, R., \& Benner, A. D. (2016). Educational pathways. In J. T. Mortimer, M. J. Shanahan, \& M. Kirkpatrick Johnson (Eds.), Handbook of the life course (Vol. 2, pp. 179-200). Cham: Springer.

*Crosta, P. M. (2014). Intensity and attachment: how the chaotic enrollment patterns of community college students relate to educational outcomes. Community College Review, 42(2), 118-142.

Elder Jr., G. H. (1985). Life course dynamics: trajectories and transitions, 1968-1980. Ithaca: Cornell University Press.

*Ewert, S. (2010). Male and female pathways through four-year colleges: disruption and sex stratification in higher education. American Educational Research Journal, 47(4), 744-773.

*Giani, M. S. (2015). The postsecondary resource trinity model: exploring the interaction between socioeconomic, academic, and institutional resources. Research in Higher Education, 56(2), 105-126.

*Goldrick-Rab, S. (2006). Following their every move: an investigation of social-class differences in college pathways. Sociology of Education, 79(1), 67-79.

*Goldrick-Rab, S., \& Pfeffer, F. T. (2009). Beyond access: explaining socioeconomic differences in college transfer. Sociology of Education, 82(2), 101-125.

Hadjar, A., \& Becker, R. (Eds.). (2009). Expected and unexpected consequences of the educational expansion in Europe and the US: theoretical approaches and empirical findings in comparative perspective. Bern: Haupt Verlag.

Hadjar, A., \& Gross, C. (Eds.). (2016). Education systems and inequalities. Bristol: Policy Press.

Harper, S. R. (2007). Using qualitative methods to assess student trajectories and college impact. New Directions for Institutional Research, 2007(136), 55-68.

Hearn, J. C. (1992). Emerging variations in postsecondary attendance patterns: an investigation of part-time, delayed, and nondegree enrollment. Research in Higher Education, 33(6), 657-687.

Horta, H. (2018). Higher-education researchers in Asia: the risks of insufficient contribution to international higher-education research. In J. Jung, H. Horta, \& A. Yonezawa (Eds.), Researching higher education in Asia (pp. 15-36). Singapore: Springer.

Hossler, D., Braxton, J., \& Coopersmith, G. (1989). Understanding student choice. In J. Smart (Ed.), Higher education: handbook of theory and research (Vol. 5, pp. 231-288). New York: Agathon Press.

*Johnson, I. Y., \& Muse, W. B. (2012). Student swirl at a single institution: the role of timing and student characteristics. Research in Higher Education, 53(2), 152-181.

*Kalogrides, D., \& Grodsky, E. (2011). Something to fall back on: community colleges as a safety net. Social Forces, 853-877.

Kerckhoff, A. C. (2001). Education and social stratification processes in comparative perspective Sociology of Education, 3-18.

Kosmützky, A., \& Krücken, G. (2014). Growth or steady state? A bibliometric focus on international comparative higher education research. Higher Education, 67(4), 457-472.

Kuh, G. D., Bean, J. P., Bradley, R. K., Coomes, M. D., \& Hunter, D. E. (1986). Changes in research on college students published in selected journals between 1969 and 1983. The Review of Higher Education, 9(2), 177192.

*Lassibille, G., \& Gómez, M. L. N. (2009). Tracking students’ progress through the Spanish university school sector. Higher Education, 58(6), 821-839.

Manski, C. F., \& Wise, D. A. (1983). College choice in America. Cambridge: Harvard University Press.

Mare, R. D. (1980). Social background and school continuation decisions. Journal of the American Statistical Association, 75(370), 295-305.

*Marti, C. N. (2008). Latent postsecondary persistence pathways: educational pathways in American two-year colleges. Research in Higher Education, 49(4), 317-336.

*McCormick, A. C. (2003). Swirling and double-dipping: new patterns of student attendance and their implications for higher education. New Directions for Higher Education, (121), 13-24.

*Meggiolaro, S., Giraldo, A., \& Clerici, R. (2017). A multilevel competing risks model for analysis of university students' careers in Italy. Studies in Higher Education, 42(7), 1259-1274.

Melguizo, T. (2011). A review of the theories developed to describe the process of college persistence and attainment. In J. Smart \& M. Paulsen (Eds.), Higher education: handbook of theory and research (Vol. 26, pp. 395-424). Dordrecht: Springer.

*Milesi, C. (2010). Do all roads lead to Rome? Effect of educational trajectories on educational transitions. Research in Social Stratification and Mobility, 28(1), 23-44.

*Noy, M., \& Zeidenberg, M. (2017). Community college pathways to the STEM workforce: what are they, who follows them, and how? New Directions for Community Colleges, 2017(178), 9-21. 
Pallas, A. M. (2003). Educational transitions, trajectories, and pathways. In J. T. Mortimer \& M. J. Shanahan (Eds.), Handbook of the life course (pp. 165-184). New York: Springer.

Reale, E. (2014). Challenges in higher education research: the use of quantitative tools in comparative analyses. Higher Education, 67(4), 409-422.

Reisel, L., \& Brekke, I. (2009). Minority dropout in higher education: a comparison of the United States and Norway using competing risk event history analysis. European Sociological Review, 26(6), 691-712.

Renn, K. A., Brazelton, G. B., \& Holmes, J. M. (2014). At the margins of internationalization: an analysis of journal articles on college student development, learning, and experiences, 1998-2011. Journal of College Student Development, 55(3), 278-294.

*Robinson, R. (2004). Pathways to completion: patterns of progression through a university degree. Higher Education, 47(1), 1-20.

Robinson, R., \& Bornholt, L. (2007). Pathways theory of progression through higher education. Australian Journal of Educational \& Developmental Psychology, 7, 49-62.

Rodríguez-Gómez, D., Meneses, J., Gairín, J., Feixas, M., \& Muñoz, J. L. (2016). They have gone, and now what? Understanding re-enrolment patterns in the Catalan public higher education system. Higher Education Research \& Development, 35(4), 815-828.

Sackmann, R., \& Wingens, M. (2001). Strukturen des Lebenslaufs (Vol. 1). Weinheim: Juventa.

Schofer, E., \& Meyer, J. W. (2005). The worldwide expansion of higher education in the twentieth century. American Sociological Review, 70(6), 898-920.

Shavit, Y., Arum, R., \& Gamoran, A. (2007). Stratification in higher education. Stanford: Stanford University Press.

*Shulruf, B., Tumen, S., \& Hattie, J. (2010). Student pathways in a New Zealand polytechnic: key factors for completion. International Journal of Vocational and Technical Education, 1(4), 67-73.

St. John, E. P., Asker, E. H., \& Hu, S. (2001). The role of finances in student choice. In M. B. Paulsen \& J. C. Smart (Eds.), The finance of higher education (pp. 419-438). New York: Algora Publishing.

Stevens, M. L., Armstrong, E. A., \& Arum, R. (2008). Sieve, incubator, temple, hub: empirical and theoretical advances in the sociology of higher education. Annual Review of Sociology, 34, 127-151.

Suri, H., \& Clarke, D. (2009). Advancements in research synthesis methods: from a methodologically inclusive perspective. Review of Educational Research, 79(1), 395-430.

Tett, L., Cree, V. E., \& Christie, H. (2017). From further to higher education: transition as an on-going process. Higher Education, 73(3), 389-406.

Tight, M. (2004). Research into higher education: an a-theoretical community of practice? Higher Education Research \& Development, 23(4), 395-411.

Tight, M. (2018). Higher education journals. Higher Education Research \& Development, 37(3), 607-619.

Tinto, V. (1975). Dropout from higher education. Review of Educational Research, 45(1), 89-125.

*Tumen, S., Shulruf, B., \& Hattie, J. (2008). Student pathways at the university: patterns and predictors of completion. Studies in Higher Education, 33(3), 233-252.

*Wang, X. (2016). Course-taking patterns of community college students beginning in STEM: Using data mining techniques to reveal viable STEM transfer pathways. Research in Higher Education, 57(5), 544-569.

Webb, O. J., \& Cotton, D. R. E. (2019). Deciphering the sophomore slump: changes to student perceptions during the undergraduate journey. Higher Education, 77(1), 173-190.

Publisher's note Springer Nature remains neutral with regard to jurisdictional claims in published maps and institutional affiliations. 